\title{
Canadian therapist trains teachers to help heal traumatized Afghan students
}

I n a small workshop on the top floor of the Help the Afghan Children office in Kabul, Afghanistan, Canadian psychotherapist Mary-Jo Land watched as an Afghan teacher drew the trauma uppermost in her mind. The woman's picture depicted an American plane bombing and killing an Afghan, while a Taliban soldier shoots into a house.

A second teacher drew a car bomb going off outside a school she passes every day, Land recalled. The bomb ripped apart some of the children who were lined up outside, patiently waiting for their turn in one of the 3-hour shifts required to rotate the thousands of students through the small schools each day.

For Land, a Cambridge, Ontario. therapist affiliated with McMaster University's Centre of Peace Studies in Hamilton, Ont., the pictures reinforced her reason for having made 2 trips, so far, to Afghanistan: to contribute to health care reconstruction.

Land's preliminary research indicates that $60 \%-70 \%$ of Afghan children demonstrate symptoms of post-traumatic stress disorder that impedes their ability to learn and remember. Teachers, too, are suffering from the disorder.

Yet, few, if any, mental health professionals are available to treat the vast numbers of children and teachers who need help.

It's why Land, working with Help the Afghan Children, a nongovernmental organization, is using an innovative story-based curriculum that she and other Canadians developed to train teachers to guide their students through the process of sharing their trauma and beginning to heal.

"There isn't any other option," Land says. "You can't possibly hire enough psychologists and psychiatrists to go over there and help an entire population of a country. You have to think of a way to reach large numbers of children and families."

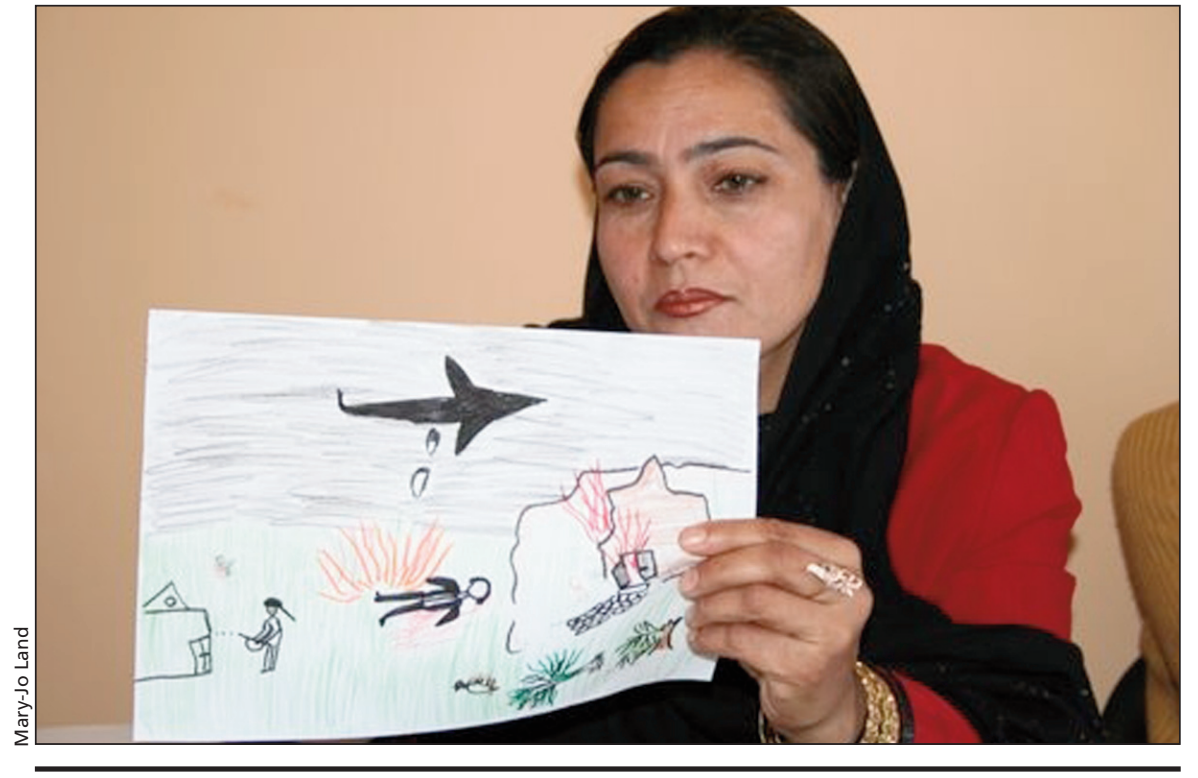

An Afghan teacher draws a picture depicting her fears.

The Journey of Peace curriculum is a sequence of 16 stories written by Land, her playwright husband Kevin, McMaster University Assistant Professory of Psychiatry Dr. Joanna Santa Barbara and McMaster University Associate Professor of Religious Studies Graeme MacQueen, with the help of Seddiq Weera, a senior adviser to the Ministry of Education in Afghanistan.

The stories, printed in illustrated books and translated into Dari and Pashtu, follow the journey of an Afghan girl and her family as they encounter land mines and survive displacement and relocation before finally returning to their village. Within the stories and a teacher training manual that Land wrote, the characters portray the symptoms of post-traumatic stress disorder, get help to cope with their symptoms in a way that is clinically accurate, follow the steps for conflict resolution and reconciliation, and learn to understand the toll that war has taken on their families.

The teacher's manual contains activities, including the use of puppets, roleplaying and drawing exercises that teachers can use in classes (www.journeyofpeace.ca). The curriculum contains different learning objectives and activities for different age groups, from grades 1 to 9 . In the early grades, teachers might concentrate on helping children deal with nightmares. In the older grades, the teachers can guide them through gender issues or ethnic differences and celebrations.

Land's role is to train master teachers, who will, in turn, train other teachers to use the curriculum.

Thus far, the curriculum has been taught as part of a pilot project at some of the 14 schools that Help the Afghan Children runs, serving about 18000 students. Land hopes to obtain funding to roll out the curriculum throughout a northern province. If a planned evaluation subsequently proves the program's efficacy, Help the Afghan Children, will ask Afghanistan's Ministry of Education to make peace education part of nationwide school curricula.

The stories tackle gender issues, schooling for girls, grief and traumatic loss, ethnic tolerance, the difficulty of 


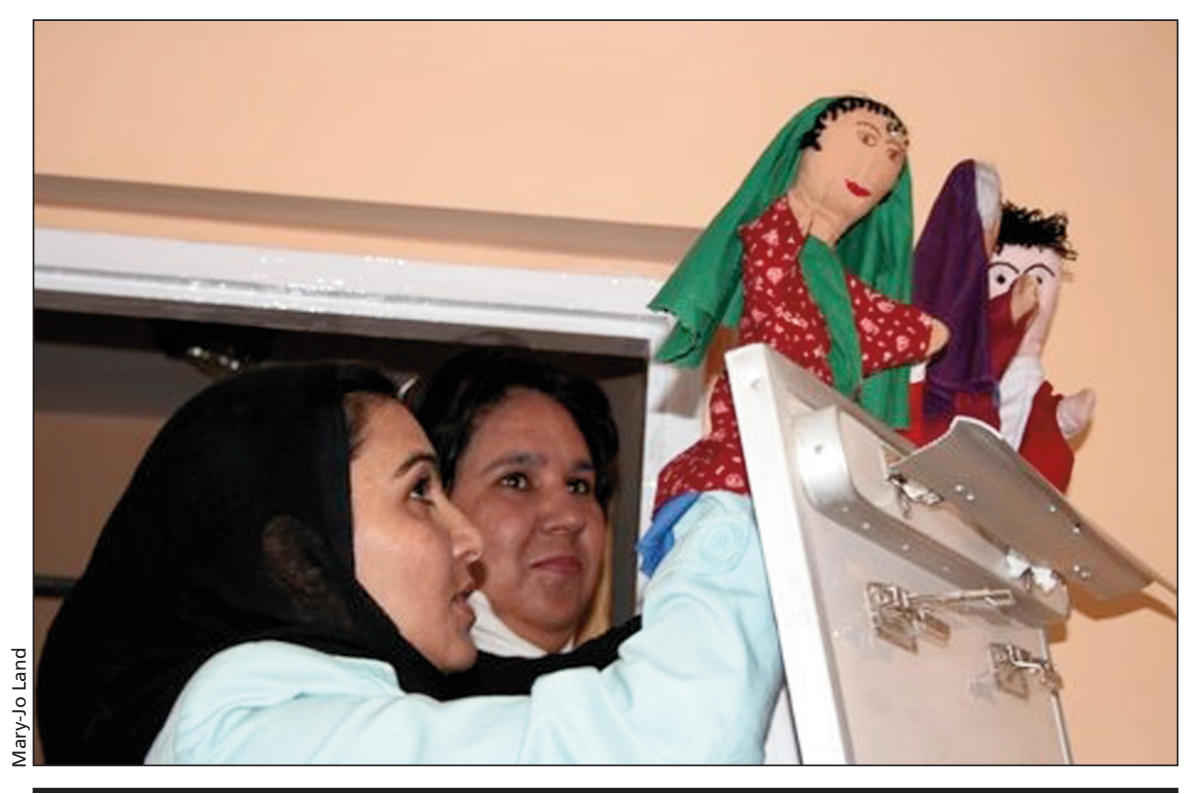

Puppets are part of the course materials that Afghan teachers are expected to eventually use in helping their pupils handle post-traumatic stress disorder.

internal displacement, occupational rehabilitation, and empathy and compassion - modelled by Bibi Jan, the main character's grandmother. The teachers come to understand that they become the "Bibi Jans" in their students' lives.

"These stories encompass a lot of problems that exist right now in Afghanistan — whether that's anger, frustration or hopelessness - the outcome of 30 years of war," says Suraya Sadeed, founder and executive director of Help the Afghan Children. "This is the best way to reach out to thousands of kids through these teachers. It's very cost-effective, and not only is it going to help the kids, it will help the families and the local communities."

During her first trip to Kabul in 2007, Land trained 50 teachers in the curriculum. She returned to train 15 other teachers at a pair of 5-day workshops from Mar. 20 to Apr. 5.

While in Afghanistan, she provided CMAJ with a running description via email — of participant responses to the workshop

One of the exercises, drawing a painful event, produced the drawing of the plane bombing that had haunted one of the pupils. But the exercise ends with instructions to draw a positive outcome, whether it's a movement to safety or a return to rebuild homes and lives.

Being able to tell a coherent narrative of your life is a marker indicating when trauma is resolved, says Land. The stories and activities should help students do just that and then go further to help families create safe havens for children in their homes — the basic building blocks for community restoration.

Although initially some teachers were skeptical that "playing with puppets" would be useful, by the time they had finished their training, some had told their life stories for the first time.

"I am comfortable to share what I have not shared with my own family," Land reports one teacher, Hafiz, as saying in an evaluation after the workshop, which Land shared with CMAJ.

Another, Maryam, talked of the "domino effect" she hoped to achieve by teaching 25 students and their families.

Still another, Arifa, said she has learned to teach "how not to let war destroy hope, faith and joy in life, that one should discuss one's problems with a trusted person."

Gulsoom, who drew the American plane bombing, said the stories not only tell of the problems of Afghanistan, but speak to solutions. "They teach hope, trust, happiness and forgiveness."

Another teacher said simply that the stories "heal the heart."

Land calls each encounter with a teacher a privilege. "You cannot fathom the hardship that these people encounter. But it's not the suffering that draws you, it's the resilience of the people."

Sayeed, an Afghan immigrant to the United States who lives in Fairfax, Virginia, considers this training preventative care. "We just have to invest in it. If they spent a fraction of the funds that go to the military for programs like this [instead], we will achieve peace in Afghanistan." — Laura Eggertson, CMAJ

DOI:10.1503/cmaj.091006 